Index Copernicus Value: 83.27 ISSN (e)-2347-176x ISSN (p) 2455-0450 crossref DOI: https://dx.doi.org/10.18535/jmscr/v5i1.55

\author{
Journal Of Medical Science And Clinical Research \\ IGM Publication \\ An Official Publication of IGM Publication
}

\title{
Serum Periostin Level in Children with Bronchial Asthma: A Comparative Study
}

\author{
Authors \\ Marwa Elhady $^{1}$, Mohamed Abdelmalik' ${ }^{2}$ Ibrahim Abu Farag ${ }^{3}$, Shahinaz Elattar ${ }^{4}$, \\ Ismail Alwakil $^{5}$ \\ ${ }^{1}$ Department of Pediatrics, Faculty of Medicine (for girls), Al-Azhar University, Cairo, Egypt \\ ${ }^{2,3}$ Department of Pediatrics, Faculty of Medicine (for boys), Al-Azhar University, Cairo, Egypt \\ ${ }^{4}$ Department of Biochemistry, Faculty of Medicine (for girls), Al-Azhar University, Cairo, Egypt \\ ${ }^{5}$ Department of Chest Diseases, Faculty of Medicine (for boys), Al-Azhar University, Cairo, Egypt
}

\begin{abstract}
Background: Assessment of pulmonary function is important for diagnosis and monitoring of bronchial asthma. The role of biomarkers in assessment of bronchial asthma is an area of increasing interest. However, debate continues on the optimal parameters to be included and the role biomarkers play in the clinical assessment of asthma.
\end{abstract}

Aim: To evaluate the role of serum periostin level for assessment of children with bronchial asthma.

Method: this comparative study included 60 asthmatics and 30 healthy children as a control group; age and sex were matched. They were classified according to severity and level of asthma control. We investigated the correlation between serum periostin level, spirometer parameters and their relation to severity of bronchial asthma and the level of control in children. Regression analysis was done to determine risk factors for impaired pulmonary function in children with asthma.

Results: serum periostin was significantly higher in asthmatics than controls and in patients with uncontrolled compared to controlled asthma. It was significantly higher in those with severe and moderate asthma than those with mild asthma. Significant negative correlation between serum periostin level and pulmonary function parameters were detected. A logistic regression analysis showed that serum periostin level was predictor of impaired forced expiratory volume 1 (FEV1) in asthmatic children with $72.22 \%$ sensitivity and $88.1 \%$ specificity.

Conclusion: Serum periostin is a promising biomarker of treatment response and disease progression that could be used for optimization of drug doses and prediction of impaired pulmonary function in children with bronchial asthma.

Keywords- periostin, children, spirometer, bronchial asthma.

\section{INTRODUCTION}

Asthma is a heterogeneous disorder characterized by acute episodic exacerbations against a background of chronic persistent inflammation associated with structural changes that may produce persistent symptoms and impaired pulmonary function. Assessment of asthma severity and level of control have become the key element in asthma management. Proper asthma treatment has been adjusted mainly on the basis of symptoms and pulmonary function ${ }^{1}$. 
Airway inflammation and remodeling contribute to irreversible airflow obstruction and airway hyperresponsiveness, and have been associated with increased disease severity and impaired pulmonary function ${ }^{2}$.

Biomarker can be used to monitor the disease progression, select optimal therapy and act as predictor for exacerbation risk and long term outcomes. Biomarkers have the advantages of being objective, quantitative, and patient-independent to avoid variation among patients in describing asthma symptoms, using rescue medication and controller therapy ${ }^{3}$.

Periostin is an extracellular matrix protein that contributes to subepithelial fibrosis. It interacts with multiple signaling cascades to modulate the expression of genes that regulate cellular interactions within the extracellular matrix. It is easily released from inflamed tissues into the circulation in response toTh2-type immune responses. Furthermore, its basal serum level is relatively low $(\sim 50 \mathrm{ng} / \mathrm{ml})$ compared to other extracellular matrix proteins. Periostien biomarker is easy to collect and measure either in serum or sputum, neither invasive nor expensive. Additionally, its level is stable with little variability which is required for a reliable biomarker ${ }^{4}$.

In contrast to adult asthma, the usefulness of periostin in childhood asthma is still under discussion. In the current study, we aim to evaluate the role of serum periostin in assessment of children with bronchial asthma in relation to pulmonary function test.

\section{PATIENTS AND METHODS}

\section{Study design}

A case control study was conducted at outpatient clinic of pediatric and chest department of AlZahraa, El Hussein and Bab El Sharia University Hospitals, Cairo, Egypt during the period between April 2015 to March 2016. The study was approved by the local Ethics Committee. Informed written parental consent was obtained prior to enrollment in the study.

\section{Study population}

A sample of 90 candidates was consecutively enrolled: 60 children with bronchial asthma and 30 healthy non asthmatic children of matched age and sex as controls. Their age ranged between $6-15$ years. Children who had upper or lower respiratory tract infections, respiratory diseases other than asthma, acute or chronic systemic illness (e.g. cardiac, renal, hepatic diseases), upper airway obstruction, thoracic cage malformation, children who refuse or unable to perform spirometer technique properly were excluded from the study. Control group included healthy children who did not have any history of wheezy chest or any allergic disorders. They fulfilled the same exclusion criteria as patient group.

\section{Methods}

\section{Clinical history and examination:}

All the studied children were subjected to a detailed history-taking and thorough clinical examination. History included: demographic data, presenting symptoms, the age of onset, the duration of disease, triggering factors, frequency and severity of acute exacerbation, presence of night symptoms, persistent symptoms in between the attacks, limitation of physical activity, history of other allergies, frequency of rescue medication, type of controller therapy, response to medication, current medications, previous hospitalization due to asthma exacerbation, symptoms suggestive of other system affection.

Chest examinations were done with recording of auscultation findings and sings of respiratory distress. Physical growth was assessed for all children by determining the weight, height, body mass index (BMI). BMI was calculated as weight (in kilograms) divided by the square of height (in meters). All the recorded measures were plotted against the Egyptian growth reference data ${ }^{5}$ to determine the centile and standard deviation. Weight and height were expressed in terms of Zscore which is a quantitative measure of the deviation of a specific percentile from the main values of age-specific population. Z-scores above 
the population mean expressed as a positive value and those below the population mean expressed as a negative value ${ }^{6}$.

According to GINA 2015 guideline $^{7}$; diagnosis of bronchial asthma was based on the symptoms of bronchospasm (cough, dyspnea and wheeze) that vary over time and intensity. Together with improvement in response to bronchodilators (increase in FEV1 of $>12 \%$ predicted). Asthma severity was evaluated by revise treatment step to control symptoms and exacerbations patients and was categorized into: mild, moderate and severe asthma. The level of asthma control was evaluated according to the frequency of symptoms, nocturnal symptoms, need of reliever medication and physical activity limitation. Patients were categorized into controlled, partly controlled or uncontrolled asthma. All the studied asthmatic children were evaluated in between attacks where pulmonary function evaluation by spirometry was done and blood sampling was taken during the same visit.

\section{Spirometry:}

All the studied children were evaluated for the pulmonary functions using Spirometry (medi soft micro 5000). Children were encouraged to blow as vigorously as possible. Spirometric-indices were calculated using best out of 3 technicallysatisfactory performances in accordance to the recommendations of American thoracic society ${ }^{8}$. Forced vital capacity (FVC), forced expiratory volume in the first second $\left(\mathrm{FEV}_{1}\right), \mathrm{FEV}_{1} \backslash \mathrm{FVC}$ ratio, Peak expiratory flow (PEF) and maximal midexpiratory flow (MMEF75/25) were measured and recorded using a spirometer by a trained, experienced chest physicians. The results were calculated as percentage of predicted ( $\%$ predicted) according to patient weight and height.

The following activities were avoided prior to spirometric study: Performing vigorous exercise within 30 minutes, wearing clothes that restrict full chest and abdominal expansion, eating large meal within 2 hours, inhaled short-acting bronchodilators, long-acting $\beta$-agonists were withheld for 6 hours and 12 hours respectively.

\section{Laboratory investigations}

Sample preparation: Serum coagulation at room temperature for $10-20 \mathrm{~min}$, centrifuge at speed of 2000-3000 rpm for $20 \mathrm{~min}$. Remove supernatant, if precipitation appeared, centrifuge again.

Sample Collection: All blood samples were collected and processed within 2 hours and stored at $-20{ }^{\circ} \mathrm{C}$ until assayed.

Assay procedure: Before the assay, the standard was diluted 5 times by pipetting 50ul standard dilution in each tube. Pipette 100ul standard $(135 \mathrm{ng} / \mathrm{ml})$ in the first tube. And take out $100 \mathrm{ul}$ from the first tube into the second. Pipette 50ul from the second tube to the third tube and produce dilution series. Repeat each of the concentration to get the mean value of each well. The blank wells were set separately (blank comparison wells don't add sample and HRP-Conjugate reagent). Samples were also diluted 5 times by pipetting sample dilution 40ul to testing sample well, then add testing sample 10ul ( sample final dilution is 5-fold), pipette sample to wells. Incubate for $30 \mathrm{~min}$ at $37^{\circ} \mathrm{C}$. Wash solution was diluted 30 -fold with distilled water. All samples were washed 5times by washing solution then we add 50ul from HRP enzyme to each well except blank. Then incubate again for $30 \mathrm{~min}$ at $37 \mathrm{C}$ then all samples were washed again 5times by washing solution. Chromogen solution (100ul) was added to each well. Stop solution (50ul) then added to each well to stop the reaction (the blue color change to yellow). The blank well is considered as zero and the absorbance was read at $450 \mathrm{~nm}$ at $15 \mathrm{~min}$ from adding stop solution

\section{Statistical Analysis}

Statistical analysis of the results was done using statistical package for social sciences (SPSS version 20.0; Chicago, IL, USA). Differences between groups were analyzed with one-way analysis of variance (ANOVA) test. Correlations were tested between serum level of periostien, absolute esinophilic count and spirometric parameters using Spearman correlation test. Liner and logistic regression analysis was done to determine the 
predictors of impaired FEV1 in asthmatic children. Receiver operating characteristic curves (ROC) were used to identify sensitivity, specificity and determine optimal cut-off points of periostien serum level for prediction of impaired FEV1 $(<60 \%)$ in asthmatic children. P-value $<0.05$ was considered to be significant.

\section{RESULTS}

This case control study included 60 children with bronchial asthma (34 males and 26 females) aged $10.82 \pm 2.35$ years old. The age of onset ranged between 4 months and 5 years with a mean duration of illness of $8.70 \pm 3.43$ years. Twenty seven of them $(45 \%)$ had history of other allergic disorder. Most of them (70\%) had positive family history of bronchial asthma. Forty five of them (75\%) received controller therapy either inhaled steroid or leukotriene antagonist. Twenty one of them had mild asthma, 22 had moderate asthma and 17 had severe asthma. Regarding the level of asthma control; 19 had controlled symptoms in the previous 6 months, 23 of them had poorly controlled asthma and 18 of them had moderately controlled asthma.

Serum periostin level was significantly higher in children with moderate and severs asthma than those with mild asthma and healthy controls. Additionally, its level was significantly higher in children with uncontrolled asthma in comparison to those with controlled asthma as demonstrated in table 1.

Pearson correlation analysis shows that the serum level of periostien had significant negative correlation with the spirometric parameters (FVC $\%$, FEV1\%, FEV1\FVC ratio, PEF, MMEF75/25) and positive correlation with absolute eosinophil count (AEC) in asthmatic children as demonstrated in Table 2.

Linear regression analysis demonstrated that there was highly statistical significant association between FEV 1, serum periostein level, eosinophil $\%$ and AEC while no statistical significant association was found with neutrophil\% or absolute neutrophil count (ANC) as shown in table 3 . However, logestic regression analysis demonstrated that serum periostein level was the only predictor for impaired FEV1 ( $<60 \%$ of predicted) with $\mathrm{p}$ value of 0.001 and odds ratio 1.019 with $95 \% \mathrm{CI}$ $(1.008-1.30)$ as shown in table 4.

At cut off point of $75 \mathrm{ng} / \mathrm{ml}$ serum periostien level had $72.22 \%$ sensitivity and $88.1 \%$ specificity for prediction of impaired FEV1 ( $<60 \%$ of predicted) in children with bronchial asthma as shown by ROC curve (figure 1).

Table (1): Comparison of serum periostien level between asthmatic children and healthy controls in relation to asthma severity and level of asthma Control

\begin{tabular}{|c|c|c|c|c|}
\hline Variables & $\begin{array}{l}\text { Mild asthma } \\
(n=21) \\
\text { Mean } \pm \text { SD }\end{array}$ & $\begin{array}{l}\text { noderate } \\
\text { asthma } \\
(\mathrm{n}=22) \\
\text { Mean } \pm \text { SD } \\
\end{array}$ & $\begin{array}{l}\text { Severe } \\
\text { asthma } \\
(n=17) \\
\text { Mean } \pm \text { SD }\end{array}$ & $\begin{array}{l}\text { Healthy } \\
\text { controls } \\
(\mathrm{n}=30) \\
\text { Mean } \pm \text { SD }\end{array}$ \\
\hline $\begin{array}{l}\text { Serum } \\
\text { periostien } \\
(\mathrm{ng} / \mathrm{ml})\end{array}$ & $\begin{array}{l}59.723 \\
\pm 4.085\end{array}$ & $\begin{array}{l}74.673 \\
\pm 44.801\end{array}$ & $\begin{array}{l}181.704 \\
\pm 83.063\end{array}$ & $\begin{array}{l}57.352 \\
\pm 2.999\end{array}$ \\
\hline $\begin{array}{l}\text { ANOVA tes } \\
\text { f } \\
\text { P-value }\end{array}$ & $\begin{array}{l}9.864 \\
<0.001 *\end{array}$ & & & \\
\hline Variables & $\begin{array}{l}\text { Controlled } \\
\text { asthma } \\
(n=19) \\
\text { Mean } \pm \text { SD }\end{array}$ & $\begin{array}{l}\text { Partially } \\
\text { controlled } \\
\text { asthma }(n=18) \\
\text { Mean } \pm \text { SD }\end{array}$ & $\begin{array}{l}\text { Uncontrolled } \\
\text { asthma } \\
(\mathrm{n}=23) \\
\text { Mean } \pm \text { SD }\end{array}$ & $\begin{array}{l}\text { Healthy } \\
\text { controls } \\
(\mathrm{n}=30) \\
\text { Mean } \pm \text { SD }\end{array}$ \\
\hline $\begin{array}{l}\text { Serum } \\
\text { periostien } \\
(\mathrm{ng} / \mathrm{ml})\end{array}$ & $\begin{array}{l}58.725 \\
\pm 4.598\end{array}$ & $\begin{array}{l}105.573 \\
\pm 68.971\end{array}$ & $\begin{array}{l}129.124 \\
\pm 90.666\end{array}$ & $\begin{array}{l}57.352 \\
\pm 2.999\end{array}$ \\
\hline $\begin{array}{l}\text { ANOVA tes } \\
\text { f } \\
\text { P-value }\end{array}$ & $\begin{array}{l}9.864 \\
<0.001 *\end{array}$ & & & \\
\hline
\end{tabular}

Table (2): Correlation between serum periostien level, AEC and spirometric findings in asthmatic children

\begin{tabular}{lll}
\hline & \multicolumn{2}{c}{ Serum periostien level } \\
\cline { 2 - 3 } & r & p-value \\
\hline AEC $($ cell/mm3) & 0.497 & $<0.0001^{*}$ \\
ANC $\left(\right.$ cell/mm $\left.\mathbf{m m}^{3}\right)$ & 0.046 & 0.666 \\
FEV1 $(\%$ of predicted) & -0.552 & $<0.0001^{*}$ \\
FVC $(\%$ of predicted) & -0.572 & $<0.0001^{*}$ \\
FEV1/FVC ratio & -0.541 & $<0.0001^{*}$ \\
PEF $(\%$ of predicted) & -0.464 & $<0.0001^{*}$ \\
MMEF75/25(\% of predicted) & -0.480 & $<0.0001^{*}$ \\
\hline
\end{tabular}

*significant

AEC: absolute eosinophil count; ANC: absolute neutrophil count; FEV1: forced expiratory volume in $1^{\text {st }}$ second; FVC: forced vital capacity; PEF: peak expiratory flow; MMEF: maximal midexpiratory flow 
Table (3): Linear regression analysis for predictors of impaired FEV1 in asthmatic children

\begin{tabular}{|c|c|c|c|c|c|}
\hline & \multicolumn{2}{|c|}{$\begin{array}{l}\text { Unstandardized } \\
\text { Coefficients }\end{array}$} & $\begin{array}{l}\text { Standardized } \\
\text { Coefficients }\end{array}$ & & \multirow{2}{*}{ P-value } \\
\hline & B & $\begin{array}{l}\text { Std. } \\
\text { Error }\end{array}$ & Beta & & \\
\hline (Constant) & 84.830 & 3.960 & & 21.422 & $<0.001 *$ \\
\hline $\begin{array}{l}\text { Serum periostin } \\
(\mathrm{pg} / \mathrm{ml})\end{array}$ & -0.154 & 0.032 & -0.534 & -4.804 & $<0.001 *$ \\
\hline $\begin{array}{l}\text { Esinophil\% } \\
\text { AEC }\left(\text { cell/mm }{ }^{3}\right) \\
\text { Neutrophil\% }\end{array}$ & $\begin{array}{l}-4.143 \\
-0.039 \\
0.366\end{array}$ & $\begin{array}{l}1.506 \\
0.014 \\
0.458\end{array}$ & $\begin{array}{l}-0.340 \\
-0.346 \\
0.104\end{array}$ & $\begin{array}{l}-2.751 \\
-2.810 \\
0.799\end{array}$ & $\begin{array}{l}0.008^{*} \\
0.007 * \\
0.427\end{array}$ \\
\hline $\mathrm{ANC}(\mathrm{cell} / \mathrm{mm} 3)$ & -0.002 & 0.002 & -0.110 & -0.844 & 0.402 \\
\hline $\begin{array}{lr}\text { Age of } \\
\text { (months) } \\
\text { Duration }\end{array}$ & t 0.103 & 0.172 & 0.078 & 0.597 & 0.553 \\
\hline illness (years) & -0.120 & 1.132 & -0.014 & -0.106 & 0.916 \\
\hline
\end{tabular}

*significant

AEC: absolute eosinophil count; ANC: absolute neutrophilic count; FEV1: forced expiratory volume in $1^{\text {st }}$ second

Table (4): Logistic regression analysis for predictors of impaired FEV1 in asthmatic children

B $\quad$ S.E. $\quad$ Wald \begin{tabular}{lll}
$\begin{array}{l}\text { P- } \\
\text { value }\end{array}$ & $\begin{array}{l}\text { Odds } \\
\text { ratio }\end{array}$ & $\begin{array}{l}95 \% \text { Cdds ratio } \\
\text { Lower Upper }\end{array}$ \\
\hline
\end{tabular}

\begin{tabular}{llllllll}
\hline $\begin{array}{l}\text { Serum periostin } \\
\text { (pg/ml) }\end{array}$ & 0.018 & 0.005 & 11.647 & 0.001 & 1.019 & 1.008 & 1.030 \\
Eosinophil\% & 0.283 & 0.173 & 2.685 & 0.101 & 1.328 & 0.946 & 1.863 \\
AEC(cell/mm ${ }^{3}$ ) & 0.002 & 0.002 & 2.448 & 0.118 & 1.002 & 0.999 & 1.005 \\
Neutrophil\% & -0.002 & 0.040 & 0.004 & 0.952 & 0.998 & 0.923 & 1.079 \\
$\begin{array}{l}\text { ANC(cell/mm3) } \\
\text { Age of onset }\end{array}$ & 0.000 & 0.000 & 0.875 & 0.349 & 1.000 & 1.000 & 1.000 \\
(months) & -0.006 & 0.018 & 0.112 & 0.738 & 0.994 & 0.960 & 1.030 \\
$\begin{array}{l}\text { Duration of } \\
\text { illness (years) }\end{array}$ & -0.033 & 0.116 & 0.083 & 0.774 & 0.967 & 0.770 & 1.214 \\
Gender & 0.486 & 0.568 & 0.729 & 0.393 & 1.625 & 0.533 & 4.952 \\
Passive smoking 0.788 & 0.588 & 1.800 & 0.180 & 2.200 & 0.695 & 6.962 \\
\hline
\end{tabular}

$\begin{array}{llllllll}\text { Passive smoking } 0.788 & 0.588 & 1.800 & 0.180 & 2.200 & 0.695 & 6.962\end{array}$

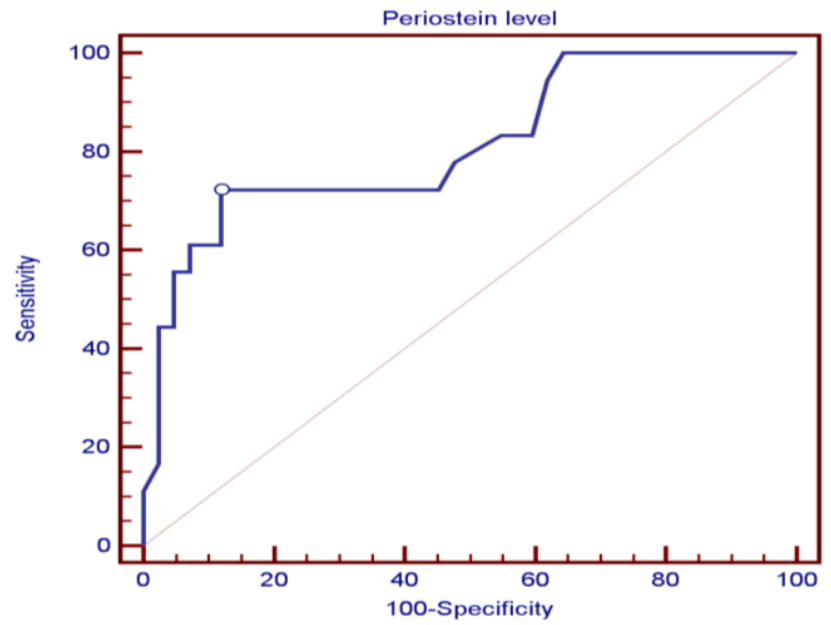

\begin{tabular}{|l|l|l|l|l|l|}
\hline Cut off point & AUC & Sensitivity & Specificity & +PV & -PV \\
\hline$>75(\mathrm{pg} / \mathrm{ml})$ & 0.813 & 72.22 & 88.10 & 72.2 & 88.1 \\
\hline
\end{tabular}

AUC: area under curve; $+\mathrm{PV}$ : positive predictive value; -PV: negative predictive value

Figure 1: ROC curve of periostien serum level for prediction of impaired FEV1 in asthmatic children

\section{DISCUSSION}

Bronchial asthma is a chronic inflammatory airway disease with airway inflammation and remodeling are the main pathological features. Clinicians should individualize the treatment regimens to prevent the development or worsening of airway remodeling ${ }^{1}$. Assessment of airway remodeling by analysis of blood and sputum biomarkers as periostin has been developed as a minimally invasive way to bypass tissue biopsy.

Our study revealed that serum periostin level was significantly correlated with asthma severity, level of asthma control, blood eosinophilia and impaired pulmonary function. Experimental studies demonstrated that periostin is linked to severe airway inflammation and hyperresponsiveness 9 . Rupani et al ${ }^{10}$ revealed that serum periostin could be a predictor of childhood asthma development. Its level is higher in children who developed asthma than those who did not develop asthma.

Our study findings were in consistent with previous adult studies. Scichilone et al ${ }^{11}$ reported that serum periostin level can discriminate between subjects with recurrent exacerbations and those in stable conditions. Nair and $\mathrm{Kraft}^{12}$ demonstrated that serum periostin level is significantly elevated in asthmatic patients with evidence of eosinophilic airway inflammation. Jia et $\mathrm{al}^{13}$ found that serum periostin is the single best systemic biomarker of airway luminal and tissue eosinophilia in severe, uncontrolled asthmatics with a positive predicted value of $93 \%$.

FEV1 is an independent predictor of asthma exacerbations; asthmatic children with a baseline FEV1 $<60 \%$ predicted have a doubled risk for asthma exacerbations in the subsequent year as compared with children with an FEV1 $>80 \%$ predicted $^{14}$.

Our study reviled a significant negative correlation between serum periostin level and FEV1 in asthmatic children. Kanemitsu et $\mathrm{al}^{15}$ reported that high serum periostin concentration $(\geq 95 \mathrm{ng} / \mathrm{ml})$ is the unique biomarker, among several serum markers, associated with the greater annual decline in FEV1 (at least $30 \mathrm{ml} /$ year). Baek et $\mathrm{al}^{16}$ reported 
that in children with exercise induced asthma, the maximum decreases in FEV1\% after exercise was positively correlated with serum periostin levels. On the other hand, Inoue et $\mathrm{al}^{17}$ demonstrated that serum periostin have not correlated either with PEFR or FEV1in children with asthma. However the previous study did not include children with severe or uncontrolled asthma.

In the current study, elevated serum periostin level could identify patients at risk of rapid FEV1 decline and asthma exacerbation despite high doses of ICS. In accordance with our findings, Bobolea et al ${ }^{18}$ found that sputum periostin levels are associated with persistent airflow limitation and eosinophilic inflammatory phenotype despite high-dose ICS therapy. There was an inverse correlation between postbronchodilator FEV1/FVC and periostin levels. These findings are in consistent with previous reports that serum periostin levels may decreased by systemic anti-inflammatory drugs but not $\mathrm{ICS}^{19}$.

Due to the heterogeneity of the disease, many biomarkers for assessment of children with bronchial asthma are available. However, periostin could signal different aspects in the pathogenesis of bronchial asthma that provide additional information for the diagnosis and management. our findings demonstrated that serum periostin level could be a valuable marker to identify asthma phenotypes, airway remodeling and treatment response.

One of the limitations of the current study is the small number of included patients. Our study was based on cross-sectional analysis, so we could not monitor the changes in serum periostin level through the course of the disease or its response to therapeutic interventions. We included children with bronchial asthma mainly depending on their level of control on treatment over the previous 6 months. Due to the explorative nature of this study, results need to be confirmed in a larger sample of patients including follow up. Another limitation is that serum periostin level could be elevated in many allergic disorders. However if we strictly exclude all children with coincident atopy, this limits the number of available asthmatic children to be included. Our study gets its strength from the significant correlation between elevated serum periostien level and impaired pulmonary function.

The standard assessment of remodeling is obtained by tissue biopsy through bronchoscopy which is costly and sophisticated invasive procedure that needs experts especially for evaluation of distal air way $^{20}$. Instead air way remodeling was assessed by measuring serum level of periostien which can assess both airway inflammation and remodeling which was correlated with air way obstruction as determined by impaired FEV1.

\section{CONCLUSIONS}

Serum periostin is a promising biomarker of treatment response and disease progression that could be used for individualization of treatment and optimization of drug dose in children with bronchial asthma. It is applicable in the clinical setting especially in children who are unable or have difficulty in performing lung function test.

\section{REFERENCES}

1. Reddel HK, Bateman ED, Becker A, et al. A summary of the new GINA strategy: a roadmap to asthma control. The European Respiratory Journal 2015; 46(3):622-639.

2. Bergeron C, Tulic MK, Hamid Q. Airway remodelling in asthma: From benchside to clinical practice. Can Respir J 2010; 17 (4): 85-93.

3. Chiappori A, De Ferrari L, Folli C, et al. Biomarkers and severe asthma: a critical appraisal. Clinical and Molecular Allergy: CMA. 2015;13:20.

4. Izuhara K, Conway SJ, Moore BB, et al. Roles of Periostin in Respiratory Disorders. Am J Respir Crit Care Med. 2016;193 (9):949-56

5. Ghalli I, Salah N, Hussein F, et al. Egyptian growth curves for infants, children and adolescents 2002. Published in: Satorio A, Buckler JMH and Marazzi N. Crecerenelmondo 2008, Ferring Publisher, Italy. 
6. Wang $\mathrm{Y}$ and Chen HJ. Use of Percentiles and Z -Scores in Anthropometry. In Preedy VR (ed.), Handbook of Anthropometry: Physical Measures 29 of Human Form in Health and Disease. Springer Science, Business Media, LLC 2012. Chapter 2:P29-48.

7. Global Initiative for Asthma. Pocket guide for health professionals. Updated 2015.

8. Miller MR, Hankinson J, Brusasco V, et al. Standardisation of spirometry. Eur Respir J. 2005;26(2):319-338.

9. Bentley JK, Chen Q, Hong JY, et al. Periostin is required for maximal airways inflammation and hyperresponsiveness in mice. J Allergy Clin Immunol. 2014;134: 1433-42.

10. Rupani H, Lau L, Ono J, et al. Serum periostin in asthma: A potential biomarker for stratification in severe treatment-resistant asthma. European Respiratory Journal 2014; 44: P3986.

11. Scichilone N, Crimi C, Benfante A, et al. Higher serum levels of periostin and the risk of exacerbations in moderate asthmatics. Asthma Research and Practice 2016; 2:1

12. Nair P, Kraft M. Serum periostin as a marker of Th2-dependent eosinophilic airway inflammation. J Allergy Clin Immunol 2012; 130:655-6.

13. Jia G, Erickson RW, Choy DF, et al. Periostin is a systemic biomarker of eosinophilic airway inflammation is asthmatic patients. J Allergy Clin Immunol 2012: 130: 647-54.

14. Fuhlbrigge AL, Kitch BT, Paltiel AD, et al. FEV1 is associated with risk of asthma attacks in a pediatric population. $\mathrm{J}$ Allergy Clin Immunol 2001; 107: 61-67.

15. Kanemitsu Y, Matsumoto H, Izuhara K, et al. Increased periostin associates with greater airflow limitation in patients receiving inhaled corticosteroids. J Allergy Clin Immunol 2013: 132: 305-12.

16. Baek H, Izuhara K, Park T. Serum Periostin Levels Correlates with Exercise-Induced
Bronchoconstriction in Asthmatic Children. Journal of Allergy and Clinical Immunology 2015, 135(2): AB151.

17. Inoue $T$, Akashi $K$, Watanabe $M$, et al. Periostin as a biomarker for the diagnosis of pediatric asthma.Pediatr Allergy Immunol. 2016;27(5):521-6.

18. Bobolea I, Barranco P, Del Pozo V, et al.Sputum periostin in patients with different severe asthma phenotypes. Allergy. 2015 May;70(5):540-6.Parulekar AD, Atik MA, Hanania NA. Periostin, a novel biomarker of TH2-driven asthma. Curr

19. Matsumoto H. Serum periostin: a novel biomarker for asthma management. Allergol Int. 2014;63:153-160.

20. Wadsworth SJ, Sin DD, Dorscheid DR. Clinical update on the use of biomarkers of airway inflammation in the management of asthma. Journal of Asthma and Allergy 2011:4 77-86. 